\title{
COPD profiles and treatable traits using minimal resources: identification, decision tree and stability over time
}

\author{
Alda Marques ${ }^{1,2^{*}}$, Sara Souto-Miranda ${ }^{1,2}$, Ana Machado ${ }^{1,2}$, Ana Oliveira ${ }^{1,3,4}$, Cristina Jácome $^{5}$, Joana Cruz ${ }^{6}$, \\ Vera Enes ${ }^{2,7}$, Vera Afreixo ${ }^{7}$, Vitória Martins ${ }^{8}$, Lília Andrade $^{9}$, Carla Valente $^{9}$, Diva Ferreira ${ }^{10}$, Paula Simão ${ }^{11}$, \\ Dina Brooks ${ }^{3,4}$ and Ana Helena Tavares ${ }^{1,2,7}$
}

\begin{abstract}
Background and objective: Profiles of people with chronic obstructive pulmonary disease (COPD) often do not describe treatable traits, lack validation and/or their stability over time is unknown. We aimed to identify COPD profiles and their treatable traits based on simple and meaningful measures; to develop and validate a decision tree and to explore profile stability over time.

Methods: An observational, prospective study was conducted. Clinical characteristics, lung function, symptoms, impact of the disease (COPD Assessment Test-CAT), health-related quality of life, physical activity, lower-limb muscle strength and functional status were collected cross-sectionally and a subsample was followed-up monthly over six months. A principal component analysis and a clustering procedure with k-medoids were applied to identify profiles. A decision tree was developed and validated cross-sectionally. Stability was explored over time with the ratio between the number of timepoints that a participant was classified in the same profile and the total number of timepoints (i.e., 6).

Results: 352 people with COPD ( $67.4 \pm 9.9$ years; $78.1 \%$ male; FEV $=56.2 \pm 20.6 \%$ predicted) participated and 90 $\left(67.6 \pm 8.9\right.$ years; $85.6 \%$ male; $F E V_{1}=52.1 \pm 19.9 \%$ predicted) were followed-up. Four profiles were identified with distinct treatable traits. The decision tree included CAT ( $<18$ or $\geq 18$ points); age $(<65$ or $\geq 65$ years) and FEV $(<48$ or $\geq 48 \%$ predicted) and had an agreement of $71.7 \%$ (Cohen's Kappa $=0.62, p<0.001$ ) with the actual profiles. $48.9 \%$ of participants remained in the same profile whilst $51.1 \%$ moved between two (47.8\%) or three (3.3\%) profiles over time. Overall stability was $86.8 \pm 15 \%$.

Conclusion: Four profiles and treatable traits were identified with simple and meaningful measures possibly available in low-resource settings. A decision tree with three commonly used variables in the routine assessment of people with COPD is now available for quick allocation to the identified profiles in clinical practice. Profiles and treatable traits may change over time in people with COPD hence, regular assessments to deliver goal-targeted personalised treatments are needed.
\end{abstract}

Keywords: Phenotype, Cluster analysis, Treatable traits, Decision trees, COPD

\footnotetext{
*Correspondence: amarques@ua.pt

${ }^{1}$ Lab3R - Respiratory Research and Rehabilitation Laboratory, School of Health Sciences, University of Aveiro (ESSUA), Agras do Crasto Campus Universitário de Santiago, Edifício 30, 3810-193 Aveiro, Portugal

Full list of author information is available at the end of the article
}

\section{Background}

Chronic obstructive pulmonary disease (COPD) is highly heterogeneous and complex hence, personalising assessments and treatments to this population across different

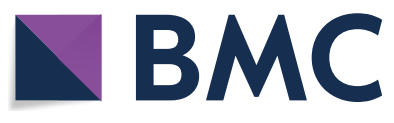
permits use, sharing, adaptation, distribution and reproduction in any medium or format, as long as you give appropriate credit to the original author(s) and the source, provide a link to the Creative Commons licence, and indicate if changes were made. The images or other third party material in this article are included in the article's Creative Commons licence, unless indicated otherwise in a credit line to the material. If material is not included in the article's Creative Commons licence and your intended use is not permitted by statutory regulation or exceeds the permitted use, you will need to obtain permission directly from the copyright holder. To view a copy of this licence, visit http://creativecommons.org/licenses/by/4.0/. The Creative Commons Public Domain Dedication waiver (http://creativeco mmons.org/publicdomain/zero/1.0/) applies to the data made available in this article, unless otherwise stated in a credit line to the data. 
settings and available resources imposes challenges and debate $[1,2]$.

Research efforts have been made to advance knowledge in this field, namely through the identification of homogeneous subgroups of patients with COPD [3, 4], the so-called clinical phenotypes or profiles, grouped by different type of personal characteristics (e.g., genetic, clinical, biochemical, radiological) for prognostic and therapeutic purposes [3-12]. More recently, a new approach, "treatable traits", i.e., pulmonary, extra-pulmonary and behaviour/lifestyle characteristics of each person that are clinically relevant, identifiable and treatable, emerged [13-15]. Although studies on clinical profiles and treatable traits have been conducted, their crosssectional nature, narrow eligibility criteria, main focus on physiological/pulmonary measures often not available across settings $[5,6]$, absence of decision trees and lack of validation with independent samples [3], limits our understanding of the heterogeneous manifestations of COPD and hinders their applicability in daily clinical practice.

Few studies have tried to identify profiles and their treatable traits using clinical and patient-reported outcomes beyond pulmonary measures and understand their behaviour over time $[9,14,15]$. Moreover, to be easily applied and useful in clinical practice, these profiles need predicting tools, such as decision trees [5]. Simple and validated decision trees are scarce but important as a first line approach, as they quickly enable the allocation of each individual into a profile $[5,10]$. Such allocation can then aid the decision-making of the most suitable comprehensive assessments to identify each person's treatable traits and guide tailored and multicomponent interventions that can alter the course/impact of the disease and its daily management $[10,13,14]$.

Thus, we aimed to (i) identify and describe profiles and respective treatable traits in people with COPD based on simple and meaningful clinical measures possible to be collected with minimal resources; (ii) develop and validate a decision tree to quickly identify the profile of each person and (iii) assess the stability of the profiles during a six-months period.

\section{Methods}

\section{Study design}

An observational, prospective cohort study was conducted with data collected between 2017 and 2020 in GENIAL (PTDC/DTP-PIC/2284/2014) and PRIME (PTDC/SAU-SER/28806/2017) projects. PRIME builds on GENIAL project, i.e., settings, recruitment strategies and data collection protocols were similar. Data were first gathered from both projects and then analysed. The study was approved by five Ethics Committees
(CHMA 09/2016-10/2018; ULS Matosinhos 10/CES/ JAS 17/02/2017-73/CE/JAS 12/10/2018; CHBV 777,638086,892; HDFF 1807/2017-27/05/2019; ARSCentro 64/2016-85/2018). This work is described according to the Strengthening the Reporting of Observational Studies in Epidemiology (STROBE) statement [16].

\section{Participants}

People with COPD diagnosed according to the GOLD criteria [17], clinically stable in previous month (i.e., no hospital admissions, acute exacerbations or changes in medication) were included. Exclusion criteria comprised the presence of other respiratory diseases or any clinical condition that precluded participation in the assessment (i.e., signs of cognitive impairment or presence of a significant cardiovascular, neurological, musculoskeletal, immunological or infectious disease). Eligible participants were identified in hospitals and primary healthcare centres routine appointments by their clinicians, who explained the study. Interested participants were contacted by the researchers who obtained written informed consents and performed data collection.

\section{Data collection}

Sociodemographic (age, sex), anthropometric (height and weight to compute body mass index [BMI]) and general clinical (smoking habits, self-reported medication for COPD, use of long-term oxygen therapy and non-invasive ventilation, number of acute exacerbations and hospitalisations in the past year) data were collected. Severity of comorbid diseases was scored with the Charlson Comorbidity Index (CCI) and interpreted as: (i) mild, 1-2; (ii) moderate, 3-4; and (iii) severe, $\geq 5$ [18]. Selfreported physical activity was assessed with the brief physical activity assessment tool (BPAAT) [19]. Scores range from 0 to 8 being interpreted as $0-3$ insufficiently active' or $\geq 4$ 'sufficiently active' [19].

Lung function was assessed with a spirometer (MicroLab 3535, CareFusion, Kent, UK) and values from the forced expiratory volume in one second $\left(\mathrm{FEV}_{1}\right)$ percentage predicted were used to classify participants' according to the GOLD grades (1, 2, 3 and 4) [17]. GOLD groups (A, B, C and D) were determined using the number of acute exacerbations and hospitalisations in the previous year and the COPD assessment Test (CAT) [17].

Impact of the disease was assessed with CAT [20]. Scores range from 0 to 40 and are interpreted as $\leq 10$ low, 11-20 medium, 21-30 high and 31-40 very high impact [20]. Activity-related dyspnoea was assessed with the modified British Medical Research Council dyspnoea questionnaire (mMRC) [21]. Scores range from 0 (no trouble with breathlessness) to 4 (too breathless to leave the house) [21]. 
Symptoms of anxiety and depression were measured with the Hospital Anxiety and Depression Scale (HADS) [22]. Scores range from 0 (minimum symptom load) to 21 (maximum symptom load) [22].

The Saint George's Respiratory Questionnaire (SGRQ) was used to measure health-related quality of life [23]. Scores range from 0 (no impairment) to 100 (worst possible health-related quality of life) [23].

Quadriceps muscle strength (QMS) was measured through a maximum voluntary isometric contraction with a handheld dynamometer [24] (microFET2, Hoggan Health, The best Salt Lake City, Utah). Measurements were taken at the dominant side [24], and the best of three measurements (less than $10 \%$ of variation) was used for analysis. Functional status was measured with the 1-min sit-to-stand test (1 minSTS) twice and the best performance was used for analysis [25]. Percentage of predicted for QMS and 1minSTS values was calculated based on reference values $[24,26]$.

These measures were chosen for their simplicity, wide availability, quick application in space constrained settings and easy identification of evidence-based treatable traits possible to tackle with non-pharmacological interventions, since our population was already receiving standard pharmacological treatment.

Data were collected during an initial visit by trained physiotherapists with more than three years of experience in similar data collection protocols. A subsample of participants was followed-up monthly over six months. Participants of different GOLD groups and grades, living within $100 \mathrm{~km}$ of our research facilities and willing to receive a physiotherapist for a short-monthly assessment at their homes were invited to participate. Data collected over the follow-up period consisted of number of acute exacerbations, hospitalisations and changes in medication in the previous month, CAT, mMRC, QMS and $1 \mathrm{minSTS}$.

\section{Statistical analysis}

All analyses were performed in $\mathrm{R}$ (version 3.6.1) with a level of significance set at $\mathrm{p}<0.05$. Normality of data distribution was tested with the Shapiro-Wilk test. Comparison between participants' characteristics and between the total and follow-up sample were analysed using t-test or Mann Whitney U-test, for continuous variables; and chi-squared or Fisher's test, for categorical variables. Differences among profile characteristics were analysed using univariate ANOVA followed by Tukey's multiple comparison test or Kruskal-Wallis test followed by Dunn's multiple comparison test, for continuous variables; and chi-squared or Fisher's test, for categorical variables, according to their assumptions.

\section{Profiles and treatable traits}

A principal component analysis was conducted to avoid strongly correlated variables dominating the cluster assignment [27]. Scores associated to the principal components yield a data matrix, on which the clustering algorithm, k-medoids, was applied [28]. The optimal number of clusters, k, was identified using the gap statistic [29] (Additional file). Age, BMI, pack years, $\mathrm{CCI}, \mathrm{FEV}_{1}$, forced vital capacity (FVC) percentage predicted, CAT, mMRC, HADS-A, HADS-D, SGRQ, QMS, and 1 minSTS were explored.

The presence/absence of treatable traits was considered as described in Table 1.

\section{Decision tree}

Random Forest was used to rank the importance of the above-mentioned 13 variables used in the clustering procedure (Additional file). The top variables were selected to construct the decision tree.

The decision tree was developed and validated with two independent data sets randomly selected from the total sample; $70 \%$ was used for generation and $30 \%$ for validation, i.e., to determine its prediction ability in identifying the correct profile [30]. The accuracy, defined as the proportion of correct classifications, was used to quantify the predictive ability of the decision tree. The decision tree that maximised accuracy was chosen.

Agreement between the profile predicted by the decision tree and the profile defined by the clustering procedure was determined using Cohen's Kappa and interpreted as: poor $(k<0)$, slight $(0.00 \leq k \leq 0.20)$, fair $(0.21 \leq \mathrm{k} \leq 0.40)$, moderate $(0.41 \leq \mathrm{k} \leq 0.60)$, substantial $(0.61 \leq \mathrm{k} \leq 0.80)$ or almost perfect $(\mathrm{k}>0.80)$ [31].

\section{Stability of the profiles over time}

The decision tree was applied in all timepoints for each participant. Stability of the profiles was assessed with a stability score defined as the ratio between the number of timepoints that a participant was classified in the same profile (most frequent profile for that participant) and the total number of timepoints (i.e., 6). Possible scores ranged from $1 / 3$ (maximum instability-migrating across the 4 profiles) to 1 (complete stability-there was no change in the profile allocation over time).

\section{Results}

A total of 523 people with COPD were recruited however, 171 had incomplete data due to participants' lack of time. Therefore, for establishing the profiles and developing the decision tree, data from 352 people with COPD $\left(67.4 \pm 9.9\right.$ years; $275[78.1 \%]$ male; $\mathrm{FEV}_{1}=56.2 \pm 20.6 \%$ predicted), were used. From these, 133 people were 
Table 1 Treatable traits, measurement instrument and cut-off values used for interpretation in people with chronic obstructive pulmonary disease

\begin{tabular}{|c|c|c|}
\hline Treatable traits & Measurement instrument & Cut-off used for interpretation \\
\hline \multicolumn{3}{|l|}{ Pulmonary traits } \\
\hline Mild airflow obstruction [17] & FEV $\%$ pred [17] & $\geqslant 80 \%$ pred $[17]$ \\
\hline Moderate airflow obstruction [17] & FEV $\%$ pred [17] & $50 \leqslant \mathrm{FEV}_{1}<80 \%$ pred [17] \\
\hline Severe airflow obstruction [17] & FEV $\%$ pred [17] & $30 \% \leqslant F E V_{1}<50 \%$ pred $[17]$ \\
\hline Very severe airflow obstruction [17] & FEV $\%$ pred [17] & $<30 \%$ pred [17] \\
\hline Frequent exacerbations & Clinical history in the previous year [17] & $\begin{array}{l}\geq 2 \text { exacerbations or } \geq 1 \text { hospitalisa- } \\
\text { tion in the previous year }[17]\end{array}$ \\
\hline \multicolumn{3}{|l|}{ Extra-pulmonary traits_-physical } \\
\hline Poor nutritional status & BMI [54] & $\mathrm{BMI}<21$ or $\mathrm{BMl}>30 \mathrm{~kg} / \mathrm{m}^{2}[54]$ \\
\hline Lower-limb muscle dysfunction & QMS measured with the HHD [24] & $<70 \%$ of percentage predicted $[24,55]$ \\
\hline Low functional status & $1 \mathrm{minSTS}[25]$ & $<70 \%$ of percentage predicted $[25,55]$ \\
\hline \multicolumn{3}{|c|}{ Extrapulmonary traits—symptoms and health status } \\
\hline Activity-related dyspnoea & $\mathrm{mMRC}[21]$ & $\geq 2$ points $[2,10,14,17]$ \\
\hline Impact of the disease & CAT [20] & $\begin{array}{l}\geq 10 \text { points }[10,14,17] \\
\geq 18 \text { points }[2]\end{array}$ \\
\hline Symptoms of anxiety & HADS [22] & $\geq 8$ points in HADS-A [22] \\
\hline Symptoms of depression & HADS [22] & $\geq 8$ points in HADS-D [22] \\
\hline Impact on health-related quality of life & SGRQ [23] & $\begin{array}{l}\geq 25 \text { points [17] } \\
\geq 46 \text { points [2] }\end{array}$ \\
\hline \multicolumn{3}{|c|}{ Extrapulmonary traits_-behavioural/life-style risk factors } \\
\hline Current smoking & Clinical history [17] & Positive at the moment of assessment \\
\hline Physical inactivity & Brief physical activity assessment tool (BPAAT) & $\leq 3$ points [19] \\
\hline
\end{tabular}

$B M I$ body mass index, BPAAT Brief physical activity assessment tool, CAT COPD Assessment Test, FEV $\%$ pred FEV , forced expiratory volume in $1 \mathrm{~s}$ percentage predicted, HADS The Hospital Anxiety and Depression Scale HADS-A anxiety subscale and HADS-D depression subscale, HHD HandHeld Dynamometry, mMRC Modified British Medical Research Council questionnaire, QMS Quadriceps muscle strength, SGRQ Saint George's Respiratory Questionnaire, 1 minSTS 1-min Sit-to-Stand Test. We used two cut-offs for CAT ( $\geq 10$ points and $\geq 18$ points) and SGRQ ( $\geq 25$ points and $\geq 46$ points): the ones currently recommended ${ }^{17}$ and the ones found to better discriminate burden of symptoms in COPD $^{2}$.

followed monthly for six months. In 43 participants, data were missing in at least one timepoint and therefore, they were excluded from the follow-up analysis. Hence, stability of the profiles was performed with data from 90 people with COPD $(67.6 \pm 8.9$ years old; 77 [85.6\%] male; $\mathrm{FEV}_{1}=52.1 \pm 19.9 \%$ predicted). Figure 1 shows the flow of participants in the study.

Four profiles were identified (Fig. 2 and Additional file 1: Figure S1). Table 2 presents baseline characteristics and treatable traits for the total sample, per profile and for the longitudinal subsample. Each profile incorporated people with COPD from all GOLD grades and groups (Additional file 1: Figure S2). Profiles 1 and 3 were composed of older, mostly overweight/obese and comorbid people. Profiles 2 and 4 included younger and underweight/normal weight people.

Profiles 1 and 2 were mostly composed of people with severe airflow obstruction, medium-high levels of dyspnoea, medium-high impact of the disease and low lower-limb muscle function, functional status and healthrelated quality of life. Profile 2 integrated the higher proportion of people on long-term oxygen therapy, with anxiety and depression symptoms, highest impact of the disease and poorest health-related quality of life.

Profiles 3 and 4 included mostly people with moderate airflow obstruction, less dyspnoeic, with low impact of the disease, high lower-limb muscle function and functional status, and better health-related quality of life. Profile 4 also presented the highest proportion of sufficiently active people. Further details are presented in Additional file 1: Figure S3.

\section{Decision tree}

The Random Forest identified CAT (cut-off 18 points), age (cut-off 65 years), and $\mathrm{FEV}_{1} \%$ predicted (cut-off $48 \%$ predicted) as the most informative variables for the decision tree (Fig. 3) of the four profiles (Additional file). The tree assigned correctly $71.7 \%$ of people with COPD to their actual profile, thus a substantial agreement (Cohen's Kappa $=0.62, \mathrm{p}<0.001)$ was observed.

\section{Stability of the profiles}

From the 90 participants followed-up, 26 (28.9\%) were in profile $1,24(26.7 \%)$ in profile $2,23(25.5 \%)$ in profile 3 


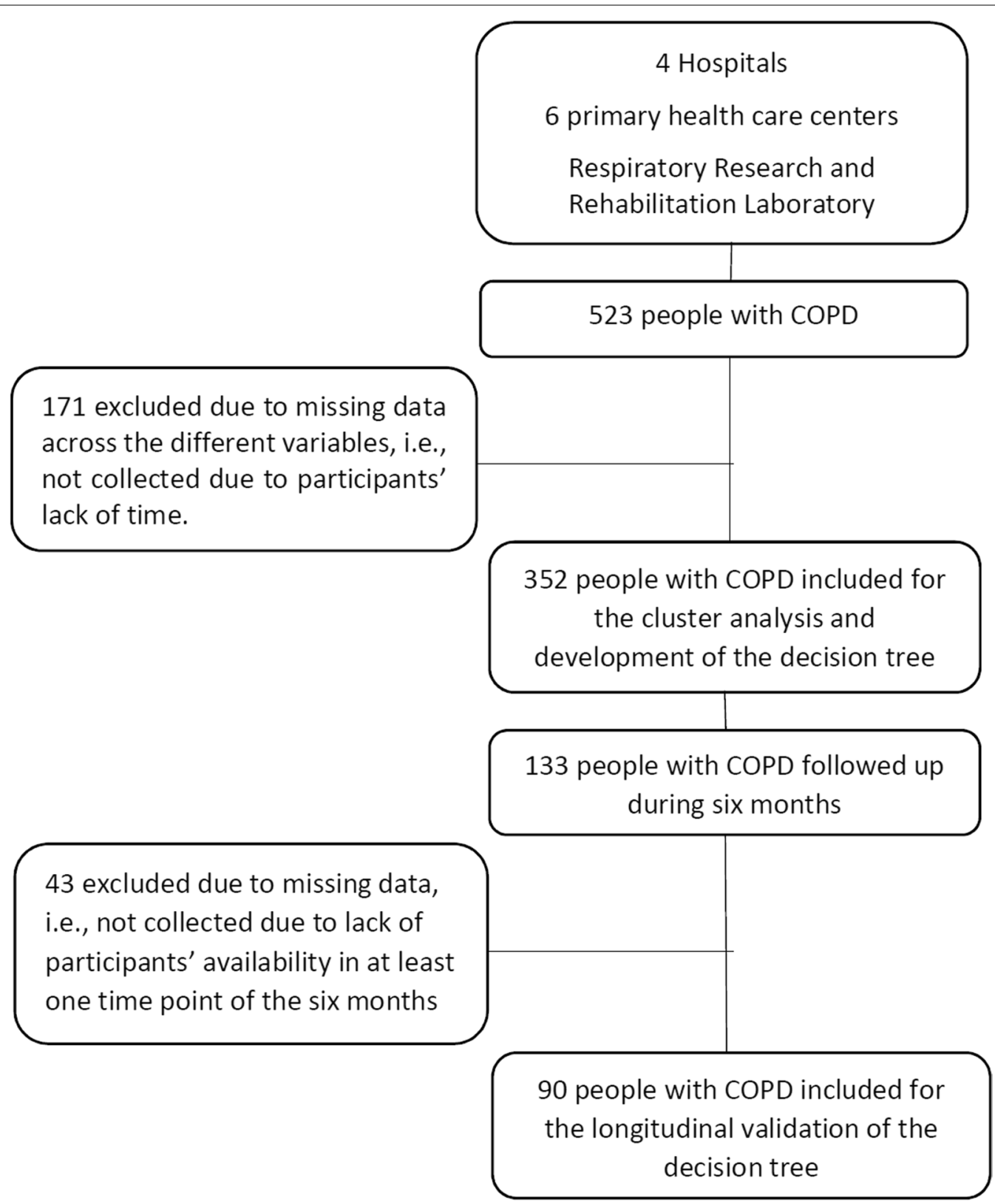

Fig. 1 Flow chart of participants' recruitment for establishing the profiles and developing and validating the decision tree $(n=352)$ as well as for studying the stability of the proposed profiles $(n=90)$ in people with chronic obstructive pulmonary disease (COPD)

and $17(18.9 \%)$ in profile 4 (Additional file 1: Table S1). $42 \%(11 / 26)$ of people in profile $1,25 \%(6 / 24)$ in profile 2 , $65 \%(15 / 23)$ in profile 3 and $71 \%(12 / 17)$ in profile 4 remained in the same profile over time. Therefore, profile 4 presented the higher stability score $(0.94 \pm 0.10)$, followed by profile $3(0.88 \pm 0.19)$, profile $1(0.85 \pm 0.14)$ and profile $2(0.83 \pm 0.13)$. Overall, $48.9 \%(n=44)$ of people remained in the same profile during the six months (stability score $=1)$. The other participants $(n=43 ; 47.8 \%)$ remained predominantly in one of the profiles (i.e., for at least 3 months) but moved between two profiles. Three participants (3.3\%) moved across three profiles over time. The overall percentage of stability was $86.8 \pm 15 \%$. Figure 4 shows the flow of participants across profiles during the follow-up.

\section{Discussion}

Four distinct profiles and respective treatable traits of people with COPD were identified and described using simple and widely available measures. Heterogeneity 


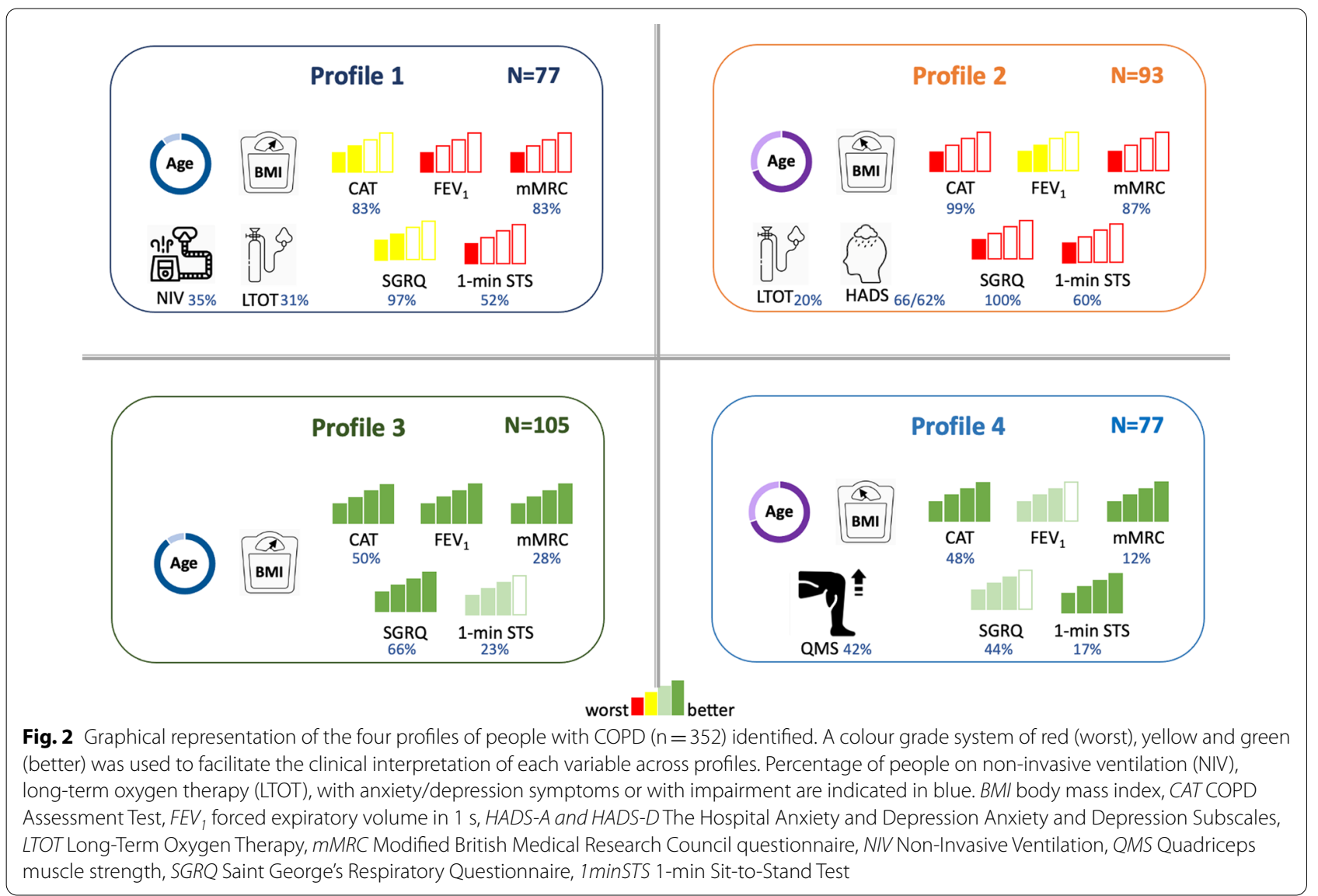

within each profile and overlap in some treatable traits existed. We proposed a simple decision tree $(\mathrm{CAT}<18$ or $\geq 18$ points; age $<65$ or $\geq 65$ years; $\mathrm{FEV}_{1}<48$ or $\geq 48 \%$ predicted) that can aid healthcare professionals in clinical practice to allocate each person to a specific profile quickly, even with minimal resources. This is of most importance, as it can rapidly guide personalised assessments and decision-making regarding the best treatments for each treatable trait. We also showed that $51.1 \%$ of the sample changed their profile over a six-month period and that those more symptomatic, with moderatehigh impact of the disease and lower limb muscle function, functional status and health-related quality of life (profiles 1 and 2) were the ones less stable in their profile. Our findings suggest that frequent assessments of people with COPD might be needed to ensure that the most adequate personalised interventions are offered.

Despite the enormous variability of published clinical phenotypes/profiles in COPD [3-12, 32], some common ground to our study seems to exist, i.e., profiles composed of older, overweight and dyspnoeic people and others with younger people with nutritional depletion $[5-7,11]$ and high as well as low impact of the disease, lower-limb muscle function, functional status and health-related quality of life may be present in people with similar airflow limitation $[5,11,12]$. Thus, our findings reinforce the previously acknowledged need to include comprehensive assessments in people with COPD, that go beyond pulmonary measures [9, 12, 15, 33]. Such assessments, even if applied with minimal resources, as demonstrated in our study, allow the easy identification of extrapulmonary treatable traits within each profile, which is of most importance for the daily management of COPD since they can be modified with person-centred interventions [14].

In our study, we were able to identify that people with COPD from profiles 1, 2 and 3 might benefit from pulmonary rehabilitation (exercise, education and psychosocial support) to target their activity-related dyspnoea, impact of disease, lower-limb muscle dysfunction and/ or functional status impairment [34]. Profiles among people with COPD who could benefit from pulmonary rehabilitation and physical activity promotion to address their symptoms, exercise intolerance and functional status impairments have been previously reported $[8,10,32$, 35-37]. Those in profiles 1 and 3 might also benefit from dietary counselling and calorie restriction plus resistance exercise training $[38,39]$ and referral for comorbidities' 
Table 2 Characteristics of people with chronic obstructive pulmonary disease (COPD), for the total sample $(n=352)$, for each of the four profiles identified and for the longitudinal subsample $(n=90)$

\begin{tabular}{|c|c|c|c|c|c|c|c|c|}
\hline & $\begin{array}{l}\text { Total sample } \\
(\mathrm{n}=352)\end{array}$ & $\begin{array}{l}\text { Profile } 1 \\
(\mathrm{n}=77)\end{array}$ & $\begin{array}{l}\text { Profile } 2 \\
(\mathrm{n}=93)\end{array}$ & $\begin{array}{l}\text { Profile } 3 \\
(n=105)\end{array}$ & $\begin{array}{l}\text { Profile } 4 \\
(n=77)\end{array}$ & $\begin{array}{l}\text { p-value } \\
\text { (comparisons } \\
\text { across profiles) }\end{array}$ & $\begin{array}{l}\text { Longitudinal } \\
\text { subsample } \\
(n=90)\end{array}$ & $\begin{array}{l}\text { p-value } \\
\text { (longitudinal } \\
\text { vs. total } \\
\text { sample) }\end{array}$ \\
\hline Age, years & $68(61-74)$ & $71(67-78)^{b, d}$ & $66(58-71)^{\mathrm{a}, \mathrm{c}, \mathrm{d}}$ & $72(69-78)^{\mathrm{b}, \mathrm{d}}$ & $59(54-64)^{a, b, c}$ & $<0.001$ & $68(62-72)$ & 0.945 \\
\hline Sex, n (\%) & & & & & & 0.1373 & & 0.1569 \\
\hline Male & $275(78.1)$ & $65(84.4)$ & $69(74.2)$ & $86(81.9)$ & $55(71.4)$ & & $77(85.6)$ & \\
\hline Female & $77(21.9)$ & $12(15.6)$ & $24(25.8)$ & $19(18.1)$ & $22(28.6)$ & & $13(14.4)$ & \\
\hline $\begin{array}{l}\text { AECOPD, n/per } \\
\text { year }\end{array}$ & $0(0-1)$ & $1(0-2)^{d}$ & $1(0-3)^{c, d}$ & $0(0-1)^{b}$ & $0(0-1)^{a, b}$ & $<0.001$ & $0(0-1)$ & 0.180 \\
\hline $\mathrm{CCl}$, score & $4(3-5)$ & $5(3-5)^{b, d}$ & $4(3-4)^{a, c, d}$ & $4(4-5)^{b, d}$ & $3(2-3)^{a, b, c}$ & $<0.001$ & $3(3-4)$ & 0.109 \\
\hline $\begin{array}{l}\text { Medication use, } \\
\mathrm{n}(\%)\end{array}$ & $276(83.1)$ & $61(84.7)$ & $79(91.9)$ & $84(84.0)$ & $52(70.3)$ & 0.003 & $66(73.3)$ & 0.252 \\
\hline SABA & $37(11.4)$ & $10(14.3)$ & $15(17.6)$ & $7(7.1)$ & $5(6.9)$ & & $10(11.1)$ & \\
\hline LABA & $53(16.3)$ & $13(18.6)$ & $19(22.4)$ & $18(18.4)$ & $3(4.2)$ & & $11(12.2)$ & \\
\hline SAMA & $16(4.9)$ & $4(5.7)$ & $9(10.6)$ & $3(3.1)$ & $0(0.0)$ & & $2(2.2)$ & \\
\hline LAMA & $90(27.7)$ & $26(37.1)$ & $23(27.1)$ & $27(27.6)$ & $14(19.4)$ & & $19(21.1)$ & \\
\hline $\begin{array}{l}\text { LABA/LAMA } \\
\text { combination }\end{array}$ & $98(30.2)$ & $18(25.7)$ & $31(36.5)$ & $30(30.6)$ & $19(26.4)$ & & $31(34.4)$ & \\
\hline ICS & $38(11.7)$ & $7(10.0)$ & $14(16.5)$ & $11(11.2)$ & $6(8.3)$ & & $13(14.4)$ & \\
\hline $\begin{array}{l}\text { ICS/LABA combi- } \\
\text { nation }\end{array}$ & $121(37.2)$ & $31(44.3)$ & $32(37.6)$ & $35(35.7)$ & $23(31.9)$ & & $30(33.3)$ & \\
\hline LTRA & $16(4.9)$ & $5(7.2)$ & $3(3.5)$ & $5(5.1)$ & $3(4.2)$ & & $4(4.4)$ & \\
\hline Xanthines & $27(8.3)$ & $14(20.0)$ & $6(7.1)$ & $3(3.1)$ & $4(5.6)$ & & $3(3.3)$ & \\
\hline Mucolytics & $22(6.8)$ & $5(7.1)$ & $9(10.6)$ & $7(7.1)$ & $1(1.4)$ & & $8(8.9)$ & \\
\hline NIV, n (\%) & $45(12.8)$ & $27(35.1)$ & $7(7.5)$ & $10(9.5)$ & $1(1.3)$ & $<0.001$ & $12(13.5)$ & 1.000 \\
\hline LTOT, n (\%) & $46(13.1)$ & $24(31.2)$ & $19(20.4)$ & $1(1.0)$ & $2(2.6)$ & $<0.001$ & $13(14.6)$ & 0.8363 \\
\hline \multicolumn{9}{|l|}{ Pulmonary traits } \\
\hline \multicolumn{9}{|l|}{ Lung function } \\
\hline $\begin{array}{l}\mathrm{FEV}_{1}, \% \text { of } \\
\text { predicted }\end{array}$ & $55.0(40.8-70.3)$ & $41(32-49)^{b, c, d}$ & $47(36-66)^{a, c, d}$ & $69(57-80)^{a, b, d}$ & $62(44-75)^{a, b, c}$ & $<0.001$ & $49.0(37.0-62.0)$ & 0.075 \\
\hline $\begin{array}{l}\mathrm{FVC}, \% \text { of } \\
\text { predicted }\end{array}$ & $80(66.0-93.8)$ & $64(53.5-70.0)^{b, c, d}$ & $78(63.0-90.3)^{\mathrm{a}, \mathrm{c}}$ & $\begin{array}{l}93(80.0- \\
105.5)^{a, b, d}\end{array}$ & $81(68.5-96.0)^{\mathrm{a}, \mathrm{c}}$ & $<0.001$ & $78.0(63.0-91.0)$ & 0.641 \\
\hline $\mathrm{FEV}_{1} / \mathrm{FVC}$ & $56.2(44.1-65.0)$ & $\begin{array}{l}50.3(41.2- \\
61.9)^{\mathrm{c}, \mathrm{d}}\end{array}$ & $\begin{array}{l}51.4(38.7- \\
62.7)^{c, d}\end{array}$ & $59.1(50-65.1)^{\mathrm{a}, \mathrm{b}}$ & $61.7(50.2-68)^{a, b}$ & $<0.001$ & $50.0(42.0-59.2)$ & 0.008 \\
\hline $\begin{array}{l}\text { GOLD grades, } \\
\mathrm{n}(\%)\end{array}$ & & & & & & $<0.001$ & & 0.196 \\
\hline 1 & $49(13.9)$ & $0(0)$ & $7(7.5)$ & $28(26.7)$ & $14(18.2)$ & & $10(11.1)$ & \\
\hline 2 & $159(45.2)$ & $18(23.4)$ & $39(41.9)$ & $65(61.9)$ & $37(48.1)$ & & $34(37.8)$ & \\
\hline 3 & $111(31.5)$ & $45(58.4)$ & $34(36.6)$ & $12(11.4)$ & $20(26.0)$ & & $34(37.8)$ & \\
\hline 4 & $33(9.4)$ & $14(18.2)$ & $13(14.0)$ & $0(0)$ & $6(7.8)$ & & $11(12.2)$ & \\
\hline $\begin{array}{l}\text { GOLD groups, } \\
\text { n (\%) }\end{array}$ & & & & & & $<0.001$ & & 0.003 \\
\hline A & $85(24.1)$ & $7(9.1)$ & $0(0)$ & $42(40.0)$ & $36(46.8)$ & & $22(24.4)$ & \\
\hline B & $166(47.2)$ & $42(54.5)$ & $51(54.8)$ & $41(39.0)$ & $32(41.6)$ & & $45(50.0)$ & \\
\hline C & $22(6.3)$ & $6(7.8)$ & $1(1.1)$ & $11(10.5)$ & $4(5.2)$ & & $4(4.4)$ & \\
\hline D & $79(22.4)$ & $22(28.6)$ & $41(44.1)$ & $11(10.5)$ & $5(6.5)$ & & $18(20.0)$ & \\
\hline \multicolumn{9}{|c|}{ Extrapulmonary traits_-physical } \\
\hline $\mathrm{BMl}, \mathrm{kg} / \mathrm{m}^{2}$ & $26.4(23.8-29.8)$ & $\begin{array}{l}29.7(26.2- \\
33.2)^{b, d}\end{array}$ & $\begin{array}{l}24.7(22.4- \\
27.9)^{\mathrm{a}, \mathrm{c}}\end{array}$ & $\begin{array}{l}27.7(25.2- \\
30.5)^{\mathrm{b}, \mathrm{d}}\end{array}$ & $24.6(22-27)^{\mathrm{a}, \mathrm{c}}$ & $<0.001$ & $26.0(23.9-29.8)$ & 0.540 \\
\hline$<21, \mathrm{n}(\%)$ & $30(8.5)$ & $0(0)$ & $13(14.0)$ & $3(2.9)$ & $14(18.2)$ & $<0.001$ & $10(11.1)$ & 0.765 \\
\hline$>30, n(\%)$ & $85(24.1)$ & $35(45.5)$ & $14(15.1)$ & $30(28.6)$ & $6(7.8)$ & & $19(21.1)$ & \\
\hline QMS, kgF & $26.2(20.4-31.6)$ & $25.7(18.3-30.8)^{d}$ & $23.9(18.2-29.6)^{d}$ & $26(21-30.3)$ & $28.6(24-33.2)^{a, b}$ & 0.002 & $31.0(23.9-36.2)$ & 0.000 \\
\hline $\begin{array}{l}<70 \% \text { of } \\
\text { predicted, } \\
n(\%)\end{array}$ & $174(49.4)$ & $48(62.3)$ & $49(52.7)$ & $45(42.9)$ & $32(41.6)$ & 0.026 & $15(16.7)$ & $<0.001$ \\
\hline
\end{tabular}


Table 2 (continued)

\begin{tabular}{|c|c|c|c|c|c|c|c|c|}
\hline & $\begin{array}{l}\text { Total sample } \\
(\mathrm{n}=352)\end{array}$ & $\begin{array}{l}\text { Profile } 1 \\
(n=77)\end{array}$ & $\begin{array}{l}\text { Profile } 2 \\
(n=93)\end{array}$ & $\begin{array}{l}\text { Profile } 3 \\
(n=105)\end{array}$ & $\begin{array}{l}\text { Profile } 4 \\
(n=77)\end{array}$ & $\begin{array}{l}\text { p-value } \\
\text { (comparisons } \\
\text { across profiles) }\end{array}$ & $\begin{array}{l}\text { Longitudinal } \\
\text { subsample } \\
(\mathrm{n}=90)\end{array}$ & $\begin{array}{l}\text { p-value } \\
\text { (longitudina } \\
\text { vs. total } \\
\text { sample) }\end{array}$ \\
\hline $\begin{array}{l}1 \mathrm{minSTS} \text {, } \\
\text { repetitions }\end{array}$ & $27(20.8-34.0)$ & $23(18-27)^{c, d}$ & $22(17-28)^{c, d}$ & $28(23-34)^{*}$ & $36(30-44)^{*}$ & $<0.001$ & $26.5(22.0-33.0)$ & 0.800 \\
\hline $\begin{array}{l}<70 \% \text { of pre- } \\
\text { dicted, } n(\%)\end{array}$ & $133(37.8)$ & $40(51.9)$ & $56(60.2)$ & $24(23.3)$ & $13(16.9)$ & $<0.001$ & $25(27.8)$ & 0.131 \\
\hline \multicolumn{9}{|c|}{ Extrapulmonary traits - symptoms and health status } \\
\hline CAT, score & $14(8-20)$ & $15(11-19)^{*}$ & $23(19-27)^{*}$ & $9(6-14)^{a, b}$ & $9(6-13)^{a, b}$ & $<0.001$ & $14.0(8.0-21.0)$ & 0.702 \\
\hline$\geq 10, \mathrm{n}(\%)$ & $245(69.6)$ & $64(83.1)$ & $92(98.9)$ & $52(49.5)$ & $37(48.1)$ & $<0.001$ & $58(64.4)$ & 0.347 \\
\hline$\geq 18, \mathrm{n}(\%)$ & $110(31.3)$ & $23(29.9)$ & $77(82.8)$ & $9(8.6)$ & $1(1.3)$ & $<0.001$ & $24(26.7)$ & 0.399 \\
\hline mMRC, score & $2(1-2)$ & $2(2-3)^{c, d}$ & $3(2-3)^{c, d}$ & $1(1-2)^{a, b}$ & $1(0-1)^{a, b}$ & $<0.001$ & $1(1-2)$ & 0.984 \\
\hline$\geq 2, n(\%)$ & $183(52.0)$ & $64(83.1)$ & $81(87.1)$ & $29(27.6)$ & $9(11.7)$ & $<0.001$ & $43(47.8)$ & 0.536 \\
\hline \multicolumn{9}{|l|}{ HADS, score } \\
\hline HADS-A & $6(3-9)$ & $5(3-7)^{\mathrm{b}}$ & $10(6-12)^{*}$ & $5(3-7)^{b}$ & $5(3-7)^{b}$ & $<0.001$ & $6.5(4.2-12.2)$ & 0.243 \\
\hline $\begin{array}{l}\text { HADS-A } \geq 8 \\
n(\%)\end{array}$ & $118(33.5)$ & $18(23.4)$ & $61(65.6)$ & $24(22.9)$ & $15(19.5)$ & $<0.001$ & $24(26.7)$ & 0.591 \\
\hline HADS-D & $6(3-9)$ & $6(3-9)^{b, d}$ & $9(6-11)^{*}$ & $5(3-8)^{b, d}$ & $3(2-5)^{*}$ & $<0.001$ & $6.0(3.0-7.0)$ & 0.697 \\
\hline $\begin{array}{l}\text { HADS-D } \geq 8 \\
n(\%)\end{array}$ & $125(35.5)$ & $29(37.7)$ & $58(62.4)$ & $30(28.6)$ & $8(10.4)$ & $<0.001$ & $21(23.3)$ & 0.130 \\
\hline \multicolumn{9}{|l|}{ SGRQ, score } \\
\hline Symptoms & $59.3( \pm 24.1)$ & $69.4( \pm 14.2)^{c, d}$ & $76.1( \pm 12.6)^{c, d}$ & $42.7( \pm 20.1)^{\mathrm{a}, \mathrm{b}}$ & $35.3( \pm 22.8)^{\mathrm{a}, \mathrm{b}}$ & $<0.001$ & $48.0( \pm 22.2)$ & 0.981 \\
\hline Activities & $35.7( \pm 21.1)$ & $41.3( \pm 14.9)^{*}$ & $51.4( \pm 14.9)^{*}$ & $24.6( \pm 18.5)^{*}$ & $13.0( \pm 10.8)^{*}$ & $<0.001$ & $55.5( \pm 26.2)$ & 0.397 \\
\hline Impact & $41.7( \pm 19.0)$ & $49.5( \pm 12.5)^{*}$ & $61.0( \pm 11.3)^{*}$ & $31.2( \pm 13.7)^{*}$ & $24.8( \pm 12.2)^{*}$ & $<0.001$ & $31.7( \pm 22.4)$ & 0.356 \\
\hline Total & $48.1( \pm 22.1)$ & $49.9( \pm 17.0)^{\mathrm{b}, \mathrm{c}}$ & $63.9( \pm 15.6)^{*}$ & $30.9( \pm 19.4)^{a, b}$ & $37.0( \pm 20.5)^{b}$ & $<0.001$ & $41.5( \pm 21.6)$ & 0.953 \\
\hline $\begin{array}{l}\text { Total } \geq 25 \\
\mathrm{n}(\%)\end{array}$ & $271(77.0)$ & $75(97.4)$ & $93(100)$ & $69(65.7)$ & $34(44.2)$ & $<0.001$ & $71(78.9)$ & 0.695 \\
\hline $\begin{array}{l}\text { Total } \geq 46, \\
n(\%)\end{array}$ & $153(43.5)$ & $45(58.4)$ & $86(92.5)$ & $18(17.1)$ & $4(5.2)$ & $<0.001$ & $34(37.8)$ & 0.412 \\
\hline \multicolumn{9}{|c|}{ Extrapulmonary traits_-behavioural } \\
\hline $\begin{array}{l}\text { Smoking } \\
\text { status, n (\%) }\end{array}$ & & & & & & $<0.001$ & & 0.192 \\
\hline Current & $52(14.8)$ & $6(7.8)$ & $13(14.0)$ & $9(8.6)$ & $24(31.2)$ & & $12(13.3)$ & \\
\hline Former & $221(62.8)$ & $52(67.5)$ & $57(61.3)$ & $66(62.9)$ & $46(59.7)$ & & $65(72.2)$ & \\
\hline Never & $79(22.4)$ & $19(24.7)$ & $23(24.7)$ & $30(28.6)$ & $7(9.1)$ & & $13(14.4)$ & \\
\hline Pack-years & $32.3(2.9-60)$ & $48(0.1-87.5)$ & $28(2-52)$ & $30(0-52.5)$ & $30(15-45)$ & 0.112 & $50.0(30.0-90.0)$ & $<0.001$ \\
\hline BPAAT, score & $1(0-4)$ & $0(0-4)^{d}$ & $0(0-4)$ & $1(0-4)$ & $2(0-4)^{a}$ & 0.003 & $1(0.5-4)$ & $<0.001$ \\
\hline $\begin{array}{l}\text { Insufficiently } \\
\text { active, n (\%) }\end{array}$ & $242(69.1)$ & $54(70.1)$ & $68(73.9)$ & $74(71.2)$ & $46(59.7)$ & 0.221 & $61(68.5)$ & 0.912 \\
\hline $\begin{array}{l}\text { Sufficiently } \\
\text { active, n (\%) }\end{array}$ & $108(30.9)$ & $23(29.9)$ & $24(26.1)$ & $30(28.8)$ & $31(40.3)$ & & $28(31.5)$ & \\
\hline
\end{tabular}

Continuous variables are expressed as mean ( \pm standard deviation) or median [first quartile-third quartile] according to their distribution. Categorical variables were expressed as absolute frequency (\%)

AECOPD acute exacerbations of COPD, BMI, body mass index, BPAAT Brief Physical Activity Assessment Tool, CCI Charlson Comorbidity Index, CAT COPD Assessment Test, FEV ${ }_{1}$ forced expiratory volume in $1 \mathrm{~s}$, FVC forced vital capacity, GOLD Global Initiative for Chronic Obstructive Lung Disease; HADS, The Hospital Anxiety and Depression Scale, LTOT Long-Term Oxygen Therapy, SABA Short-Acting Beta Agonists, SAMA Short-acting muscarinic-antagonist; LABA Long-acting beta-agonists, LAMA Long-acting muscarinic antagonists, ICS Inhaled corticosteroids, LTRA Leukotriene receptor antagonist, $m M R C$ Modified British Medical Research Council questionnaire, NIV Non-Invasive Ventilation, QMS Quadriceps muscle strength, SGRQ Saint George's Respiratory Questionnaire; $1 \mathrm{minSTS}$, 1-min Sit-to-Stand Test * $p<0.05$ when compared with all other profiles

${ }^{a} p<0.05$ vs Profile 1

${ }^{\mathrm{b}} \mathrm{p}<0.05$ vs Profile 2

${ }^{c} p<0.05$ vs Profile 3

$\mathrm{d} p<0.05$ vs Profile 4

management [40], due to their high BMI and severity of comorbidities. Indeed, different body composition and comorbidity profiles which involve several body systems in people with COPD have been acknowledged and 




Fig. 3 Decision tree to assign people with chronic obstructive pulmonary disease (COPD) to the identified profiles (1, 2, 3 and 4). Cut-off points were 18 for the COPD Assessment Test (CAT), 65 years for age and $48 \%$ of predicted for the forced expiratory volume in $1 \mathrm{~s}($ FEV $)$. Pie charts represent the proportion of people with COPD correctly assigned to each profile using the decision tree (using the actual profile provided in Fig. 2 as the criterion)

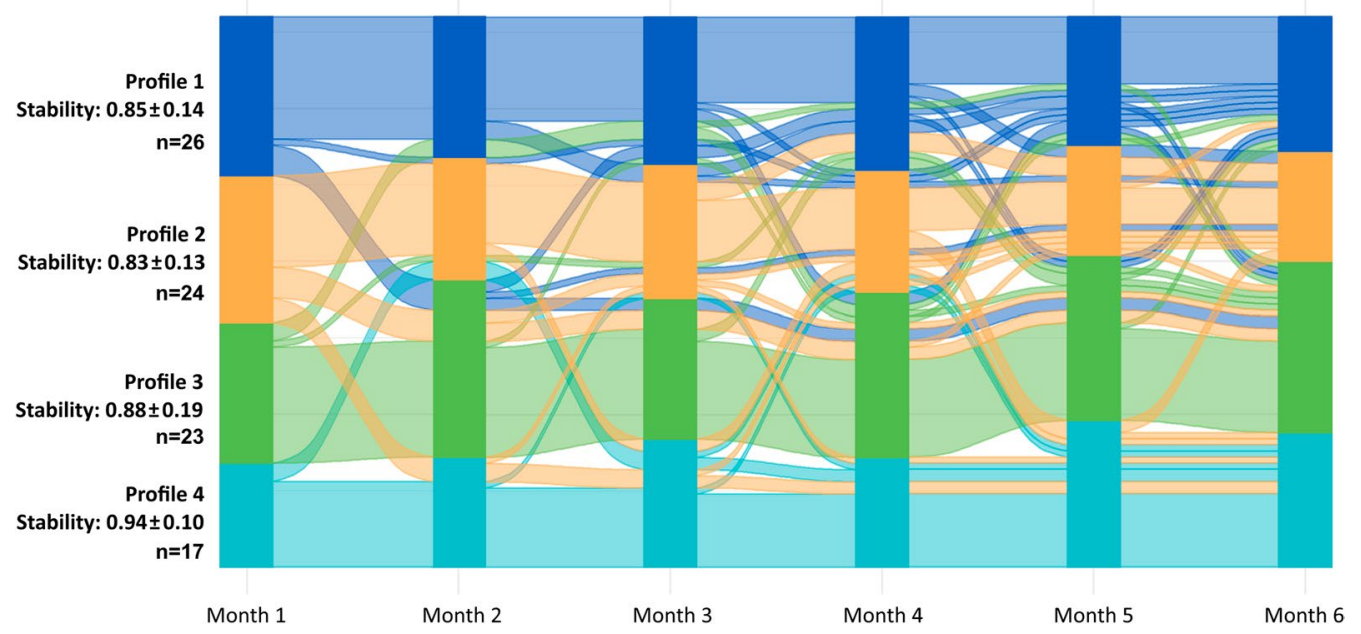

Fig. 4 Flow of people with chronic obstructive pulmonary disease $(n=90)$ across profiles $(1,2,3$ and 4$)$ during the six-month follow-up period

multidisciplinary care approaches advocated $[7,41]$. People in profile 2 showed the worst emotional status. This was not surprising, as a specific emotionally dysfunctional cluster has been previously identified in people with COPD [9]. People in profile 2 might benefit from a specific psychological assessment and possibly cognitive behavioural therapy $[42,43]$. Lastly, people in profile 4 exhibit much better health status than those in the other 
profiles, indicating that physical activity counselling [44] and self-management programmes [45] might be the most appropriate interventions as well as nutritional support to manage their underweight [46]. In fact, regular physical activities in the local community have been recommended for older people with COPD who integrate the profile of no or low disease burden and better health status [10]. This recommendation is based on the rationale that any additional increase in physical activity and decrease in sedentary behaviour is important to improve health outcomes in this population [47, 48].

The proposed and validated simple decision tree facilitates the identification of these profiles in clinical practice. Similar cut-offs have been previously proposed: for CAT when referring to exercise-based interventions[10] and to better differentiate symptom burden in COPD [2]; as well as for age [5] and for $\mathrm{FEV}_{1} \%$ predicted when predicting mortality [49], which suggests that these cut-offs might be the most adequate to differentiate health status of people with COPD. The quick allocation of each person to a profile can aid decision-making regarding prioritisation of assessments and identification of specific targets to improve patient-related outcomes [10], saving time and financial resources spent in first assessments. However, it should never preclude healthcare professionals from conducting individual comprehensive assessments $[9,12]$.

Our work also emphasised the need for regular assessments as we found that $51.1 \%$ of people with COPD assigned to one profile changed to another over time, and hence some of their treatable traits might have changed too. Migration across profiles within one [49] or two [50] years has been previously observed, mainly driven by changes in symptoms (CAT), lung function $\left(\mathrm{FEV}_{1}\right)$, functional status (Six-minute walking test) [50] and physical activity levels [49]. Our findings show that this variability was especially evident in the more "deteriorated" profiles, mainly due to changes in the CAT score, and confirms that not all patients progress unfavourably $[49,50]$. It is already known that dramatic changes can occur over time in variables that capture patients' real life, such as symptoms (e.g., fatigue) and functional status [51], whilst $\mathrm{FEV}_{1}$ remains relatively stable [52]. In fact, the profile of patients with COPD with prolonged hospitalizations has been found not to be associated with disease severity assessed by lung function [53]. Therefore, identifying and tackling extrapulmonary treatable traits as early as possible seems fundamental to optimise outcomes in COPD, independently of the resources available. Reasons causing the shift among our profiles (e.g., change in lifestyle, acute exacerbation occurrence) would be of interest but it was beyond the scope of our study. The literature on the variability/stability of profiles and respective treatable traits over time is yet scarce and further investigation is warranted.

Strengths of our study include the integration of people with COPD from all GOLD grades and groups, living in the community, being a good representation of their daily lives. Our findings are prevenient from comprehensive assessments based on simple and widely available measures, and a simple decision tree to identify each profile and respective treatable traits is provided. Variability of each profile was evaluated over time, showing the need of personalising assessments and their frequency.

Limitations of this study include the relatively small number of participants included and proportion of females in our sample. All efforts were conducted to avoid missing data. To minimise participants' transportation and discomfort, data were mostly collected during their routine appointments with their clinician (at the hospital or primary healthcare centre), where time, space and equipment constraints exist. This decision had, however, implications in our study as often participants were not available to complete the full assessments. Conducting the assessment in a separate occasion of the regular appointment and/or agreeing to collect data in two different moments, could minimise this constraint. Nevertheless, data gathered in this work represents approximately $5 \%$ of the COPD population in our country and were collected across different settings and geographic regions, representing real-world data. Similar samples with unbalance proportion of female/male have been widely reported in COPD profiles $[5-7,11]$ however, we acknowledge that this may limit the findings to all people with COPD. Our follow-up period was also relatively short, limiting our understanding about the impact of profile migration in the overall disease development and important outcomes (e.g., risk of exacerbations). Longer longitudinal studies, with the inclusion of a higher proportion of females, and exploring associations with clinically relevant variables are warranted to confirm and further develop our findings. We did not include people who dropped out from follow-up as we wanted to assess stability of the profiles and respective treatable traits, thus we are unable to infer if the profile of those lost to follow-up differed from those included. Although we performed a comprehensive assessment, many other important measures could be considered when profiling and identifying treatable traits in people with COPD (e.g., fatigue impairment, sleep disturbances, sedentary behaviour)[14]. Core treatable traits in COPD and efficacy of targeting treatments to them are yet unknown but should be addressed in future investigations. 


\section{Conclusion}

Four profiles and their treatable traits were identified in people with COPD using minimal resources. A simple decision tree (CAT $<18$ or $\geq 18$ points; age $<65$ or $\geq 65$ years; $\mathrm{FEV}_{1}<48$ or $\geq 48 \%$ predicted) is now available to facilitate routine allocation of people to these profiles. Heterogeneity within each profile and overlap in treatable traits existed, as well as migration across profiles (51.1\% of the sample) over time, especially in those more symptomatic and with worse functional status. Our findings provide additional evidence emphasising the need of frequent personalised assessments to identify treatable traits and ensure the most adequate personcentred intervention is offered to people with COPD. Nevertheless, future research namely on the validation of our decision tree and profiles in other samples would be beneficial.

\section{Take home message}

Profiles and treatable traits in COPD can be identified even with minimal resources. People with COPD may change profile and treatable traits over time hence, regular assessments to deliver goal-targeted personalised treatments are needed.

\section{Abbreviations}

1 minSTS: 1-Min sit-to-stand test; BMI: Body mass index; BPAAT: Brief physical activity assessment tool; CAT: COPD assessment test; CCl: Charlson comorbidity index; COPD: Chronic obstructive pulmonary disease; FEV $F_{1}$. Forced expiratory volume in one second; GOLD: Global initiative for chronic obstructive lung disease; HADS: Hospital anxiety and depression scale; HADS-A: Hospital anxiety and depression scale-anxiety subscale; HADS-D: Hospital anxiety and depression scale-depression subscale; mMRC: Modified British Medical Research Council dyspnoea questionnaire; QMS: Quadriceps muscle strength; SGRQ: Saint George's respiratory questionnaire.
\end{abstract}

\section{Supplementary Information}

The online version contains supplementary material available at https://doi. org/10.1186/s12931-022-01954-6.

Additional file 1. An additional file provides more details on the statistical analysis performed and further information on the results for GAP statistics, sample characteristics and distribution.

\section{Acknowledgements}

The authors are very grateful to all people with COPD for participating in this study.

\section{Authors' contributions}

AM conceived and designed the work, was responsible for obtaining the funding and ensured project administration and resources. AM, CJ, JC, VA, VM, $L A, C V$, PS obtained the funding. SSM, AFM, AO performed data collection. VM $L A, C V, D F, P S$ assessed participants for eligibility criteria and referred them to the study. CJ, JC and DB contributed for the project conception. DB also provided consultancy during the project development. AM, AFM, SSM, VE, VA and AHT performed data analysis. AM, SSM, AFM interpreted the data. AM drafted the manuscript. All authors critically revised the manuscript, ensured accuracy and integrity of the work, approved the final version to be published, and agreed to be accountable for all aspects of the work. All authors read and approved the final manuscript.

\section{Funding}

This work was funded by Programa Operacional de Competitividade e Internacionalização-POCI, through Fundo Europeu de Desenvolvimento Regional_FEDER (POCI-01-0145-FEDER-007628 and POCI-010145-FEDER-028806), Fundação para a Ciência e Tecnologia (PTDC/ DTP-PIC/2284/2014 and PTDC/SAU-SER/28806/2017) and under projects UIDB/04501/2020 and UIDB/04106/2020

\section{Availability of data and materials}

The database used to produce this paper will not be shared because further analyses are still being conducted. Nevertheless, additional information on the data will be provided upon request to the authors.

\section{Declarations}

\section{Ethics approval and consent to participate}

The study was approved by five Ethics Committees (CHMA 09/2016-10/2018; ULS Matosinhos 10/CES/JAS 17/02/2017-73/CE/JAS 12/10/2018; CHBV 777638-086892; HDFF 1807/2017-27/05/2019; ARSCentro 64/2016-85/2018). Informed consents were obtained from all participants before any data collection.

\section{Consent for publication}

Not applicable.

\section{Competing interests}

The authors declare that they have no competing interests.

\section{Author details}

${ }^{1}$ Lab3R - Respiratory Research and Rehabilitation Laboratory, School of Health Sciences, University of Aveiro (ESSUA), Agras do Crasto - Campus Universitário de Santiago, Edifício 30, 3810-193 Aveiro, Portugal. ${ }^{2}$ iBiMED - Institute of Biomedicine, Department of Medical Sciences, University of Aveiro, Agras do Crasto - Campus Universitário de Santiago, Edifício 30, 3810-193 Aveiro, Portugal. ${ }^{3}$ School of Rehabilitation Science, McMaster University, Hamilton, Canada. ${ }^{4}$ West Park Healthcare Centre, Toronto, Canada. ${ }^{5}$ Center for Health Technology and Services Research (CINTESIS) and Department of Community Medicine, Information and Health Decision Sciences (MEDCIDS), Faculty of Medicine, University of Porto, Porto, Portugal. ${ }^{6}$ Centre for Innovative Care and Health Technology (ciTechCare), Polytechnic of Leiria, Leiria, Portugal. ${ }^{7}$ Center for Research \& Development in Mathematics and Applications (CIDMA), University of Aveiro, Aveiro, Portugal. ${ }^{8}$ Pulmonology Department, Hospital Distrital Figueira Foz, Figueira da Foz, Portugal. ${ }^{9}$ Pulmonology Department, Centro Hospitalar do Baixo Vouga, Aveiro, Portugal. ${ }^{10}$ Pulmonology Department, Centro Hospitalar do Médio Ave, Famalicão, Portugal. ${ }^{11}$ Pulmonology Department, Unidade Local de Saúde de Matosinhos, Matosinhos, Portugal.

Received: 19 October 2021 Accepted: 8 February 2022

Published online: 14 February 2022

\section{References}

1. Agusti A. The path to personalised medicine in COPD. Thorax. 2014:69:857-64.

2. Smid DE, Franssen FME, Gonik M, Miravitlles M, Casanova C, Cosio BG, de Lucas-Ramos P, Marin JM, Martinez C, Mir I, et al. Redefining cut-points for high symptom burden of the global initiative for chronic obstructive lung disease classification in 18,577 patients with chronic obstructive pulmonary disease. J Am Med Dir Assoc. 2017;18:1097. e1011-1097.e1024

3. Nikolaou V, Massaro S, Fakhimi M, Stergioulas L, Price D. COPD phenotypes and machine learning cluster analysis: a systematic review and future research agenda. Respir Med. 2020;171:106093. 
4. Pinto LM, Alghamdi M, Benedetti A, Zaihra T, Landry T, Bourbeau J. Derivation and validation of clinical phenotypes for COPD: a systematic review. Respir Res. 2015;16:50.

5. Burgel PR, Paillasseur JL, Janssens W, Piquet J, Ter Riet G, Garcia-Aymerich J, Cosio B, Bakke P, Puhan MA, Langhammer A, et al. A simple algorithm for the identification of clinical COPD phenotypes. Eur Respir J. 2017;50:1701034.

6. Rennard SI, Locantore N, Delafont B, Tal-Singer R, Silverman EK, Vestbo J, Miller BE, Bakke P, Celli B, Calverley PM, et al. Identification of five chronic obstructive pulmonary disease subgroups with different prognoses in the ECLIPSE cohort using cluster analysis. Ann Am Thorac Soc. 2015:12:303-12.

7. Vanfleteren LE, Spruit MA, Groenen M, Gaffron S, van Empel VP, Bruijnzeel PL, Rutten EP, Op 't Roodt J, Wouters EF, Franssen FM: Clusters of comorbidities based on validated objective measurements and systemic inflammation in patients with chronic obstructive pulmonary disease. Am J Respir Crit Care Med 2013, 187:728-735

8. Xavier RF, Pereira A, Lopes AC, Cavalheri V, Pinto RMC, Cukier A, Ramos EMC, Carvalho CRF. Identification of phenotypes in people with COPD: influence of physical activity, sedentary behaviour, body composition and skeletal muscle strength. Lung. 2019;197:37-45.

9. Augustin IML, Spruit MA, Franssen FME, Gaffron S, van Merode F, Wouters EFM. Incorporating comprehensive assessment parameters to better characterize and plan rehabilitation for persons with chronic obstructive pulmonary disease. J Am Med Dir Assoc. 2020;21:1986-1991.e1983.

10. Spruit MA, Van't Hul A, Vreeken HL, Beekman E, Post MHT, Meerhoff GA, Van der Valk AL, Zagers C, Sillen MJH, Vooijs M, et al. Profiling of patients with COPD for adequate referral to exercise-based care: the Dutch model. Sports Med. 2020;50:1421-9.

11. Burgel PR, Paillasseur JL, Caillaud D, Tillie-Leblond I, Chanez P, Escamilla R, Court-Fortune I, Perez T, Carré P, Roche N. Clinical COPD phenotypes: a novel approach using principal component and cluster analyses. Eur Respir J. 2010;36:531-9.

12. Augustin IML, Spruit MA, Houben-Wilke S, Franssen FME, Vanfleteren L, Gaffron S, Janssen DJA, Wouters EFM. The respiratory physiome: Clustering based on a comprehensive lung function assessment in patients with COPD. PLOS ONE. 2018;13:e0201593.

13. McDonald VM, Fingleton J, Agusti A, Hiles SA, Clark VL, Holland AE, Marks GB, Bardin PP, Beasley R, Pavord ID, et al. Treatable traits: a new paradigm for 21st century management of chronic airway diseases: treatable traits down under international workshop report. Eur Respir J. 2019:53:1802058

14. van 't Hul AJ, Koolen EH, Antons JC, de Man M, Djamin RS, In 't Veen J, Simons SO, van den Heuvel M, van den Borst B, Spruit MA: Treatable traits qualifying for nonpharmacological interventions in COPD patients upon first referral to a pulmonologist: the COPD sTRAITosphere. ERJ Open Res 2020, 6:00438-02020.

15. Sarwar MR, McDonald VM, Abramson MJ, Paul E, George J. Treatable traits in an English cohort: prevalence and predictors of future decline in lung function and quality of life in COPD. ERJ Open Res. 2021;7:00934-2020.

16. von Elm E, Altman DG, Egger M, Pocock SJ, Gøtzsche PC, Vandenbroucke JP. The Strengthening the Reporting of Observational Studies in Epidemiology (STROBE) statement: guidelines for reporting observational studies. J Clin Epidemiol. 2008;61:344-9.

17. Global Initiative for Chronic Obstructive Lung Disease. Global strategy for the diagnosis, management, and prevention of chronic obstructive pulmonary disease (2022 report). 2022

18. Charlson M, Szatrowski TP, Peterson J, Gold J. Validation of a combined comorbidity index. J Clin Epidemiol. 1994;47:1245-51.

19. Marshall AL, Smith BJ, Bauman AE, Kaur S. Reliability and validity of a brief physical activity assessment for use by family doctors. Br J Sports Med. 2005:39:294-7.

20. Jones PW, Tabberer M, Chen WH. Creating scenarios of the impact of COPD and their relationship to COPD Assessment Test (CAT) scores. BMC Pulm Med. 2011;11:42.

21. Bestall JC, Paul EA, Garrod R, Garnham R, Jones PW, Wedzicha JA. Usefulness of the Medical Research Council (MRC) dyspnoea scale as a measure of disability in patients with chronic obstructive pulmonary disease. Thorax. 1999;54:581-6.

22. Zigmond AS, Snaith RP. The hospital anxiety and depression scale. Acta Psychiatr Scand. 1983;67:361-70.
23. Jones PW, Quirk FH, Baveystock CM. The St George's respiratory questionnaire. Respir Med. 1991;85:25-31.

24. Bohannon RW. Reference values for extremity muscle strength obtained by hand-held dynamometry from adults aged 20 to 79 years. Arch Phys Med Rehabil. 1997;78:26-32.

25. Bohannon RW, Crouch R. 1-Minute Sit-to-Stand Test: systematic review of procedures, performance and clinimetric properties. J Cardiopulm Rehabil Prev. 2019;39:2-8.

26. Strassmann A, Steurer-Stey C, Lana KD, Zoller M, Turk AJ, Suter P, Puhan MA. Population-based reference values for the 1-min sit-to-stand test. Int J Public Health. 2013;58:949-53.

27. Abdi H, Williams LJ. Principal component analysis. J Wiley Interdiscip Rev. 2010;2:433-59.

28. Dodge Y. Statistical data analysis based on the L1-norm and related methods. 2012; XII, 456 Statistics for Industry and Technology, Birkhäuser, Basel. https://doi.org/10.1007/978-3-0348-8201-9.

29. Tibshirani $R$, Walther $G$, Hastie T. Estimating the number of clusters in a data set via the gap statistic. J R Stat Soc Series B Stat Methodol. 2001;63:411-23.

30. Uçar MK, Nour M, Sindi H, Polat K. The effect of training and testing process on machine learning in biomedical datasets. Math Probl Eng. 2020;2020:1-17.

31. Watson PF, Petrie A. Method agreement analysis: a review of correct methodology. Theriogenology. 2010;73:1167-79.

32. Furlanetto KC, Pinto IF, Sant'Anna T, Hernandes NA, Pitta F. Profile of patients with chronic obstructive pulmonary disease classified as physically active and inactive according to different thresholds of physical activity in daily life. Braz J Phys Ther. 2016;20:517-24.

33. Celli BR, Cote CG, Marin JM, Casanova C, Montes de Oca M, Mendez RA, Pinto Plata V, Cabral HJ:The body-mass index, airflow obstruction, dyspnea, and exercise capacity index in chronic obstructive pulmonary disease. N Engl J Med 2004, 350:1005-1012.

34. Rochester CL, Vogiatzis I, Holland AE, Lareau SC, Marciniuk DD, Puhan MA, Spruit MA, Masefield S, Casaburi R, Clini EM, et al. An official American Thoracic Society/European Respiratory Society Policy statement: enhancing implementation, use, and delivery of pulmonary rehabilitation. Am J Respir Crit Care Med. 2015;192:1373-86.

35. Mesquita R, Spina G, Pitta F, Donaire-Gonzalez D, Deering BM, Patel MS, Mitchell KE, Alison J, van Gestel AJ, Zogg S, et al. Physical activity patterns and clusters in 1001 patients with COPD. Chron Respir Dis. 2017;14:256-69.

36. Geidl W, Carl J, Cassar S, Lehbert N, Mino E, Wittmann M, Wagner R, Schultz K, Pfeifer K. Physical activity and sedentary behaviour patterns in 326 persons with COPD before starting a pulmonary rehabilitation: a cluster analysis. J Clin Med. 2019. https://doi.org/10.3390/jcm8091346.

37. Koreny M, Demeyer H, Benet M, Arbillaga-Etxarri A, Balcells E, BarberanGarcia A, Gimeno-Santos E, Hopkinson NS, De Jong C, Karlsson N, et al. Patterns of physical activity progression in patients with COPD. Arch Bronconeumol (Engl Ed). 2021;57:214-23.

38. Schols AM, Ferreira IM, Franssen FM, Gosker HR, Janssens W, Muscaritoli M, Pison C, Rutten-van Mölken M, Slinde F, Steiner MC, et al. Nutritional assessment and therapy in COPD: a European Respiratory Society statement. Eur Respir J. 2014:44:1504-20.

39. McDonald VM, Gibson PG, Scott HA, Baines PJ, Hensley MJ, Pretto JJ, Wood LG. Should we treat obesity in COPD? The effects of diet and resistance exercise training. Respirology. 2016;21:875-82.

40. Hillas G, Perlikos F, Tsiligianni I, Tzanakis N. Managing comorbidities in COPD. Int J Chron Obstruct Pulmon Dis. 2015;10:95-109.

41. Akmatov MK, Ermakova T, Holstiege J, Steffen A, von Stillfried D, Bätzing J. Comorbidity profile of patients with concurrent diagnoses of asthma and COPD in Germany. Sci Rep. 2020;10:17945.

42. Pollok J, van Agteren JE, Esterman AJ, Carson-Chahhoud KV. Psychological therapies for the treatment of depression in chronic obstructive pulmonary disease. Cochrane Database Syst Rev. 2019:3:Cd012347.

43. Farver-Vestergaard I, O'Toole MS, O'Connor M, Løkke A, Bendstrup E, Basdeo SA, Cox DJ, Dunne PJ, Ruggeri K, Early F, Zachariae R. Mindfulnessbased cognitive therapy in COPD: a cluster randomised controlled trial. Eur Respir J. 2018. https://doi.org/10.1183/13993003.02082-2017.

44. Mantoani LC, Rubio N, McKinstry B, MacNee W, Rabinovich RA. Interventions to modify physical activity in patients with COPD: a systematic review. Eur Respir J. 2016;48:69-81. 
45. Lenferink A, Brusse-Keizer M, van der Valk PD, Frith PA, Zwerink M, Monninkhof EM, van der Palen J, Effing TW. Self-management interventions including action plans for exacerbations versus usual care in patients with chronic obstructive pulmonary disease. Cochrane Database Syst Rev. 2017:8:Cd011682.

46. Collins PF, Stratton RJ, Elia M. Nutritional support in chronic obstructive pulmonary disease: a systematic review and meta-analysis. Am J Clin Nutr. 2012;95:1385-95.

47. Benatti FB, Ried-Larsen M. The effects of breaking up prolonged sitting time: a review of experimental studies. Med Sci Sports Exerc. 2015;47:2053-61.

48. Warburton DE, Bredin SS. Reflections on physical activity and health: what should we recommend? Can J Cardiol. 2016;32:495-504.

49. Esteban C, Arostegui I, Aburto M, Moraza J, Quintana JM, García-Loizaga A, Basualdo LV, Aramburu A, Aizpiri S, Uranga A, Capelastegui A. Chronic obstructive pulmonary disease subtypes transitions over time. PLoS ONE. 2016;11:e0161710.

50. de Torres JP, Marin JM, Martinez-Gonzalez C, de Lucas-Ramos P, Cosio B, Casanova C. The importance of symptoms in the longitudinal variability of clusters in COPD patients: A validation study. Respirology. 2018;23:485-91

51. Casanova C, Aguirre-Jaíme A, de Torres JP, Pinto-Plata V, Baz R, Marin JM, Divo M, Cordoba E, Basaldua S, Cote C, Celli BR. Longitudinal assessment in COPD patients: multidimensional variability and outcomes. Eur Respir J. 2014:43:745-53.

52. Peters JB, Heijdra YF, Daudey L, Boer LM, Molema J, Dekhuijzen PN, Schermer TR, Vercoulen JH. Course of normal and abnormal fatigue in patients with chronic obstructive pulmonary disease, and its relationship with domains of health status. Patient Educ Couns. 2011;85:281-5.

53. Abd El-Qader E, Israeli-Shani L, Epstein Shochet G, Dovrish Z, King DA, Dahan D, Wand O, Shitrit D. The profile of COPD patients with prolonged hospitalizations: a retrospective analysis of 200 hospital admissions. Isr Med Assoc J. 2020;22:618-22.

54. Guo Y, Zhang T, Wang Z, Yu F, Xu Q, Guo W, Wu C, He J. Body mass index and mortality in chronic obstructive pulmonary disease: a dose-response meta-analysis. Medicine. 2016;95:e4225-e4225.

55. Koolen EH, van Hees HW, van Lummel RC, Dekhuijzen R, Djamin RS, Spruit MA. "Can do" versus "do do": a novel concept to better understand physical functioning in patients with chronic obstructive pulmonary disease. J Clin Med. 2019;8:340.

\section{Publisher's Note}

Springer Nature remains neutral with regard to jurisdictional claims in published maps and institutional affiliations.

Ready to submit your research? Choose BMC and benefit from:

- fast, convenient online submission

- thorough peer review by experienced researchers in your field

- rapid publication on acceptance

- support for research data, including large and complex data types

- gold Open Access which fosters wider collaboration and increased citations

- maximum visibility for your research: over 100M website views per year

At BMC, research is always in progress.

Learn more biomedcentral.com/submissions 